\title{
Adverse reproductive health outcomes in a cohort of young women with breast cancer exposed to systemic treatments
}

\author{
Cristina Silva ${ }^{1 *}$ (D), Ana Cristina Ribeiro Rama ${ }^{2,3}$, Sérgio Reis Soares ${ }^{4}$, Mariana Moura-Ramos ${ }^{5,6}$ and \\ Teresa Almeida-Santos ${ }^{5,7,8}$
}

\begin{abstract}
Background: Breast cancer is the most common cancer in young women. Fortunately current survival rates of BC are significant which makes future fertility very important for quality of life of BC survivors. Chemotherapy carries a significant risk of infertility in BC patients so it is important to support fertility preservation decisions in premenopausal women. Amenorrhea has long been used as a surrogate marker of infertility in cancer patients but more reliable ovarian reserve $(\mathrm{OR})$ markers are available. This study aimed to prospectively measure levels of OR in a cohort of young women with breast cancer exposed to chemotherapy, to identify adverse reproductive health outcomes in this population and to assess the influence of patient and treatment-related factors in those outcomes.

Methods: This prospective observational study included premenopausal women with breast cancer aged 18-40 years at diagnosis and proposed for (neo) adjuvant chemotherapy. Patients were evaluated before, during and a minimum of 9 months after the end of chemotherapy. Reproductive health outcomes: menses, hormonal and ultrasound OR markers, recovery of ovarian function and Premature Ovarian Insufficiency (POI).

Results: A total of 38 patients were included (mean age $32.9 \pm 3.5$ years). Levels of OR significantly decreased during the study. At the last follow up, 35 patients had AMH below the expected values for age; eight presented postmenopausal FSH; ten had not recovered their ovarian function and five met the defined criteria for POI. Age and baseline $\mathrm{AMH}$ were positively correlated with $\mathrm{AMH}$ at the last follow-up. AMH levels were higher in the group of patients treated with trastuzumab and lower in those under hormonal therapy, at the last follow-up.

Conclusions: Significant effects of systemic treatments on several reproductive outcomes and a strong relation of those outcomes with patient's age and baseline level of AMH were observed. Our results point to a possible lower gonadotoxicity when treatment includes targeted therapy with trastuzumab. Also, this investigation highlights the lack of reliable OR markers in women under hormonal therapy.
\end{abstract}

Keywords: Breast cancer, Chemotherapy, Ovarian reserve, Anti-mullerian hormone, Infertility, Oncofertility, Premature ovarian insufficiency, Fertility preservation

\footnotetext{
* Correspondence: tina.silva@sapo.pt

${ }^{1}$ Pharmacology Department, Faculty of Pharmacy, University of Coimbra,

Coimbra, Portugal

Full list of author information is available at the end of the article
}

(c) The Author(s). 2019 Open Access This article is distributed under the terms of the Creative Commons Attribution 4.0 International License (http://creativecommons.org/licenses/by/4.0/), which permits unrestricted use, distribution, and reproduction in any medium, provided you give appropriate credit to the original author(s) and the source, provide a link to the Creative Commons license, and indicate if changes were made. The Creative Commons Public Domain Dedication waiver (http://creativecommons.org/publicdomain/zero/1.0/) applies to the data made available in this article, unless otherwise stated. 


\section{Background}

Breast cancer $(\mathrm{BC})$ is the most frequent cancer among women, with an estimated 1.67 million new diagnoses in 2012 [1]. Although most cases are diagnosed in women older than 40 years of age, $\mathrm{BC}$ is also the leading type of cancer in younger women, with an incidence around $6.6 \%$, being also the most lethal [2,3]. Still, in women with $\mathrm{BC}$ under the age of 40 , survival rates range from 72 to $85 \%[4,5]$. Young $\mathrm{BC}$ women are often treated with chemotherapy $(\mathrm{CT})$ regimens that include cyclophosphamide, anthracyclines and a taxane. Other systemic therapies like targeted therapy (TT) and hormonal therapy $(\mathrm{HT})$ are also frequently used, sequentially or in combination with CT. However, much is still to be known about the effects of specific combinations of systemic therapies for BC on fertility. While cyclophosphamide and anthracyclines are recognized gonadotoxics, it is not definitely established if the addition of a taxane contributes to the gonadotoxicity of CT [6]. As for TT agents, data is limited although some clinical studies do not indicate ovarian toxicity $[7,8]$ and HT extends treatments for up to 10 years, further narrowing the reproductive window of $\mathrm{BC}$ patients.

In this context, the assessment of the risk of infertility in women with $\mathrm{BC}$ and their reproductive counselling can be challenging tasks. There is a clear need to prospectively collect data on the reproductive health outcomes of $\mathrm{BC}$ patients exposed to modern systemic therapies, using reliable fertility markers, to support an informed and shared decision on fertility preservation (FP). Female reproductive potential is mainly dictated by the ovarian reserve (OR) which can be estimated through surrogate markers. Amenorrhea is currently known to be a poor and late marker of damaged ovarian function [9]. The AntiMullerian Hormone (AMH), produced by the granulosa cells of growing follicles and the Antral Follicle Count (AFC), are highly inter-correlated measures and currently recognized as the most specific OR markers [10-12].

The aims of this study were to prospectively measure levels of OR markers in a cohort of young women with $\mathrm{BC}$ exposed to chemotherapy, associated or not to other systemic treatments; to identify adverse reproductive health outcomes in this population; and to assess the influence of patient and treatment-related factors in those outcomes.

\section{Methods}

\section{Patients and study design}

This prospective observational study was conducted at the Center for Fertility Preservation (CFP) of the Coimbra Hospital and University Centre (CHUC, EPE). Patients included were premenopausal women with $\mathrm{BC}$, aged 18-40 years at the time of diagnosis and proposed for (neo) adjuvant CT. Exclusion criteria were metastatic
$\mathrm{BC}$, pregnancy, levels of $\mathrm{AMH}$ below the quantification limit or history of previous gonadotoxic chemo/radiotherapy. Women with $\mathrm{BC}$ that were scheduled for a first consultation for FP counselling in the CFP were invited to participate. Recruitment took place between July 2014 and September 2016 and all participants signed an informed consent. The study received approval by the institutional ethics committee and the Portuguese Data Protection Authority. Hormonal (Follicle-Stimulating Hormone, FSH, and $\mathrm{AMH}$ ) and ultrasound (AFC) markers of OR were assessed at several time points before, during and after CT (Fig. 1). Demographic, reproductive and clinical data were collected at recruitment (by interview and review of clinical records) and updated at subsequent appointments during and after CT.

\section{Reproductive health outcomes Menses and ovarian reserve markers}

Self-reported menstrual data was collected at the time of recruitment and updated at subsequent appointments. Amenorrhea was defined as the absence of menstrual periods and oligomenorrhea as menstrual periods occurring at intervals of more than 35 days.

Blood samples for hormonal assays were drawn regardless of the phase of the menstrual cycle. All samples were centrally analysed for AMH and FSH levels at the Clinical Pathology Department of CHUC, EPE. AMH was measured by the UltraSensitive AMH ELISA assay kit (Ansh Labs) with a Limit of Quantification (LoQ) of $0.06 \mathrm{ng} / \mathrm{mL}$. FSH was measured by the ADVIA Centaur ${ }^{\circ}$ FSH immunoassay, with a LoQ of $0.3 \mathrm{mIU} / \mathrm{mL}$.

Antral follicle count (AFC) by intravaginal ultrasound was performed by experienced gynaecologists, following published recommendations [13] but regardless of the phase of the menstrual cycle. AFC was not performed in participants were under ovarian suppression.

\section{Recovery of ovarian function}

Recovery of ovarian function after CT was defined as: 1) return of menses and recovery of at least one of the measures of OR (FSH level $\leq 25 \mathrm{mIU} / \mathrm{mL}$ or $\mathrm{AMH}$ level $\geq$ baseline level/expected median level for age or $\mathrm{AFC} \geq$ baseline level/ expected median count for age) or 2) the occurrence of pregnancy. The expected $\mathrm{AMH}$ levels and AFC according to age were set based on median results obtained by Seifer [14] and Almog [15], correspondingly.

This outcome was not assessed in women with premenopausal FSH levels that were exposed to some form of HT, as published data is not conclusive on the influence of tamoxifen and $\mathrm{GnRH}$ agonists on hormonal levels [16-24]. 


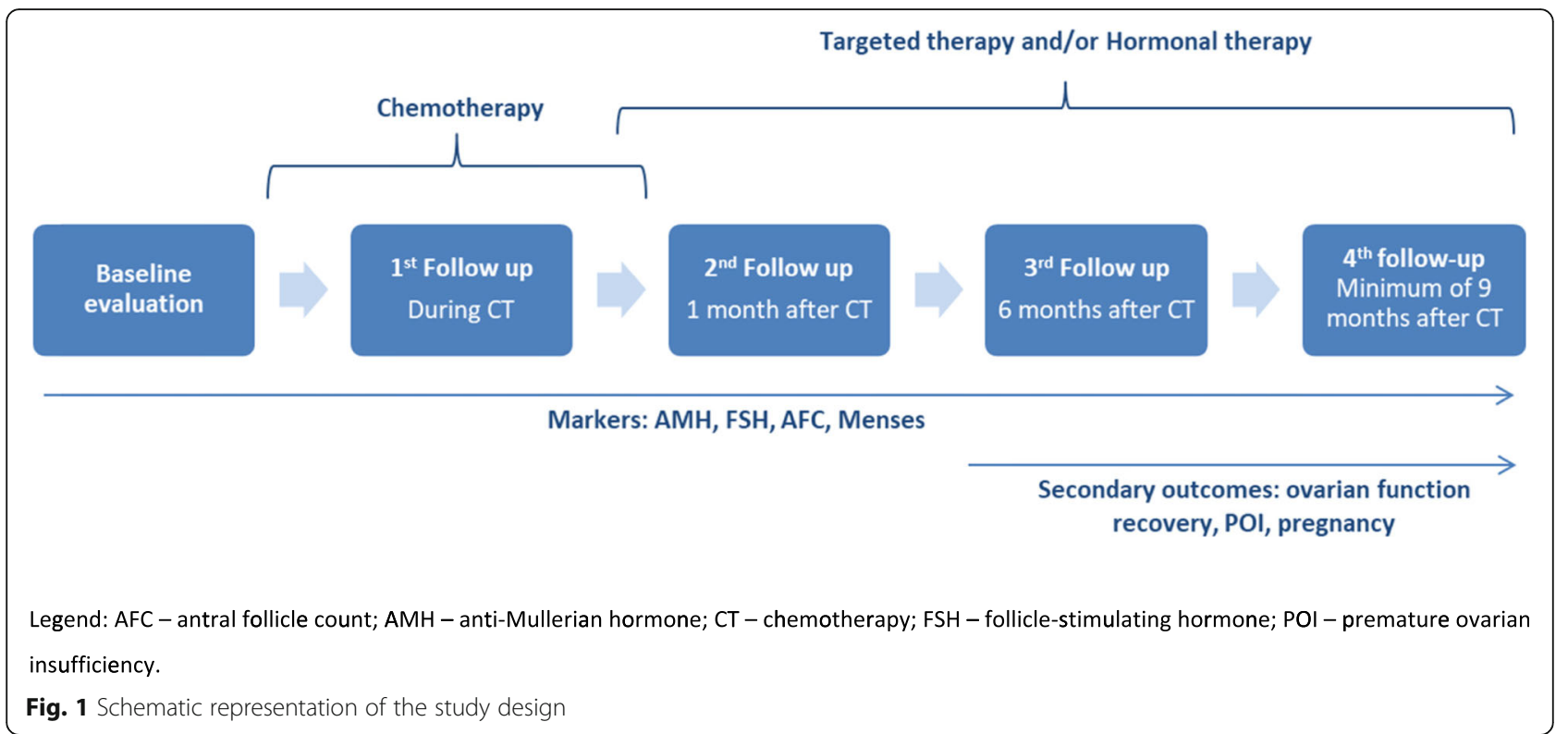

\section{Premature ovarian insufficiency}

According to the recommendations from the European Society of Human Reproduction and Embryology [25], POI was defined as the occurrence of oligo/amenorrhea for at least 4 months and elevated FSH serum levels (> $25 \mathrm{IU} / \mathrm{L}$ ) on two occasions more than 4 weeks apart, after CT. Amenorrheic patients under ovarian suppression were not evaluated for this outcome.

\section{Statistical analysis}

The analysis was performed with the software Statistical Package for Social Sciences (SPSS) version 21.

Non-parametric tests were used due to the small sample size and deviation from normality of most variables. Spearman's Rho $(\rho)$ was used to test the association between variables. Mann- Whitney and Kruskall-Wallis tests were used to compare 2 and 3 or more groups, respectively. Paired sample analysis was conducted using the Wilcoxon signed-rank test. The significance level was set at 0.05. All measurements of AMH below the limit of quantification $(\mathrm{LoQ}=0.06 \mathrm{ng} / \mathrm{mL})$ were assigned the value of $0.06 \mathrm{ng} / \mathrm{mL}$.

\section{Results}

\section{Patients' characteristics and cancer treatments}

A total of 46 women were recruited (Fig. 2). Median age of participants at study inclusion was of 33 years (mean $32.9 \pm 3.5$ years; min 25 -max 39 ). The last follow-up occurred at a mean of 18 months (range 6-35 months) after the end of CT and a mean of 2 years (range 1-3 years) after recruitment.

Demographic, clinical and fertility preservation data for the 38 participants are detailed in Table 1. Most women $(32 / 38 ; 84 \%)$ received an anthracycline-based chemotherapy regimen followed by a taxane. CT duration varied from 12 to 24 weeks with a median of 18 weeks.

Twenty nine participants performed fertility preservation through the use of one or more techniques, mainly oocyte cryopreservation $(n=25)$. Two women cryopreserved embryos, two underwent ovarian tissue cryopreservation and two were prescribed a GnRH agonist. At the end of the study none of the participants had attempted to get pregnant through the use of their cryopreserved cells or ovarian tissue.

\section{Reproductive health outcomes Menses}

All patients reported regular menses at the time of recruitment. At the last follow-up, 25 in a total of 35 patients (71\%) reported amenorrhea or oligomenorrhea. Most of these amenorrheic patients were under ovarian suppression $(n=16)$. Among the ten patients reporting menses, seven $(7 / 10 ; 70 \%)$ presented decreased OR (AMH levels below the normal for their age and/or FSH levels $>25 \mathrm{mIU} / \mathrm{mL}$ ).

\section{Ovarian reserve markers}

Evolution of ovarian reserve markers Table 2 presents the mean levels of AMH, AFC and FSH measured at baseline, during $\mathrm{CT}$, at a mean of 27 days after the end of $\mathrm{CT}$ and at each patient's last available follow-up (mean of 18 months after the end of CT). At baseline, levels of $\mathrm{AMH}$ and AFC were strongly inter-correlated $(\rho=0.656 ; p<0.001)$ and negatively correlated with patient's age (AMH, $\rho=-0.41, p=0.01$; AFC, $\rho=-0.37$, $p=0.028)$. 


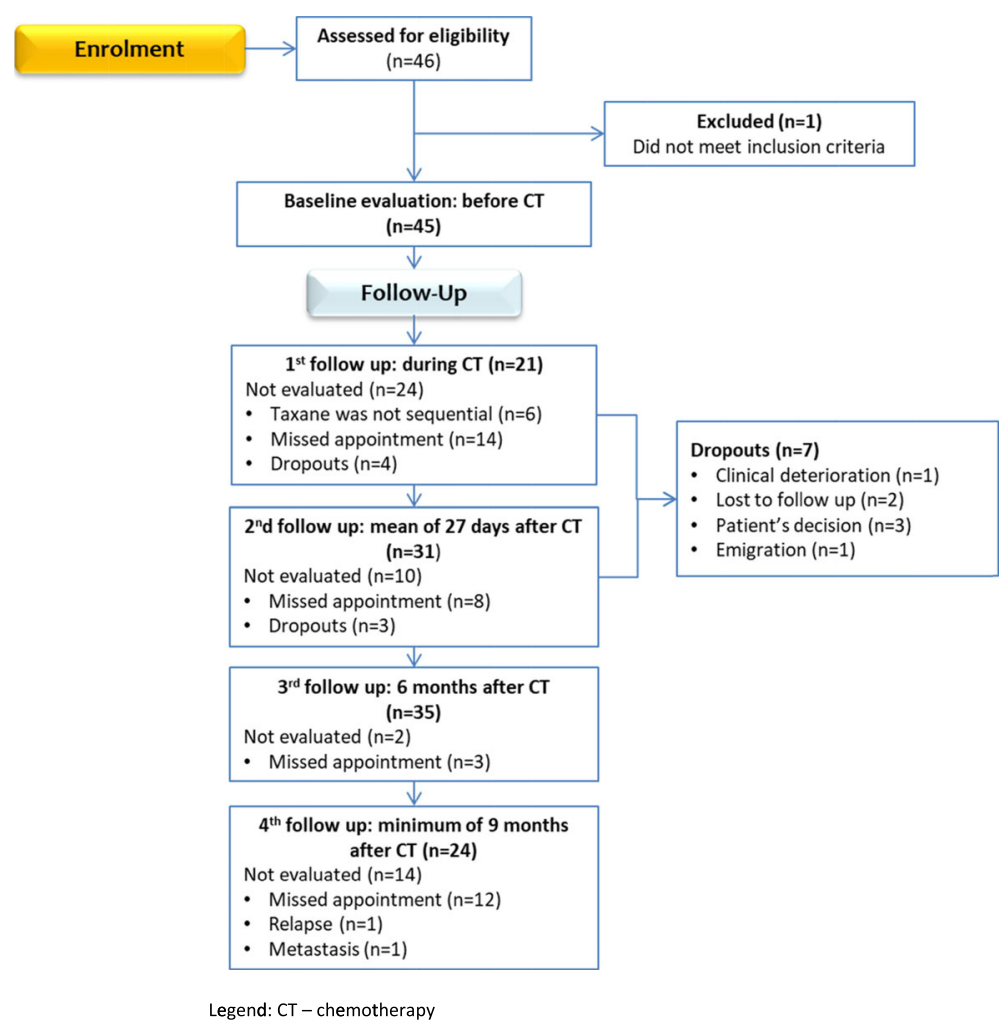

Fig. 2 Flow diagram of participation in the study

Anti-Mullerian hormone (AMH). The levels of AMH significantly decreased from baseline to the post-CT follow-ups, both at 1 month $(\mathrm{z}=-4.78, p<0.001)$ and at a mean of 18 months after CT $(\mathrm{z}=-4.9 ; p<0.001)$. However, a significant increase of AMH levels between these two last follow-ups was noticed $(\mathrm{z}=-2.9, p=0.003)$. The number of patients with AMH levels below the LoQ increased from 12 during CT to 28 at 1 month after CT, and then decreased to 21, at the last follow-up. Still, at the end of the study, 30 patients $(30 / 35 ; 86 \%)$ had AMH levels below the expected values for age and only one had recovered to baseline levels.

Antral follicle count (AFC). At baseline, 35 patients performed AFC and 16 presented normal counts considering the expected values for their age $(16 / 35 ; 46 \%)$. The number of performed counts was reduced to 21 , at the last available follow-up, mainly due to ovarian suppression. Mean AFC progressively and significantly decreased until the last follow-up $(\mathrm{z}=-3.9, p<0.001)$. No patient recovered to their initial AFC and only one presented an AFC above the normal median value for her age, at her last follow-up (28 months after the end of CT).

Follicle-stimulating hormone .Although a high variability was observed, the levels of FSH significantly increased at the follow-up 1 month after CT $(n=28$; $\mathrm{z}=-4.2, p<0.001)$ although a significant decrease was found at last follow-up $(\mathrm{z}=-3.8, p<0.001)$. Still, at the last follow-up, eight participants $(8 / 30 ; 27 \%)$ had levels consistent with menopausal status $(>25 \mathrm{mIU} / \mathrm{mL})$. No significant correlations were found between FSH levels at the last follow-up and time to follow-up ( $\rho=0.035 ; p=0.881$ ), baseline FSH $(\rho=0.235 ; p=0.181)$ or patients' age $(\rho=$ $0.125 ; p=0.474)$.

Ovarian reserve markers at the last follow-up $A M H$ and AFC levels at the last follow-up were positively and significantly inter-correlated $(n=21 ; \rho=0,429 ; p=0.05)$. Figure 3 gives a general insight on how the levels of OR markers compared with the corresponding levels expected according to patient's age (for AMH, AFC) or the defined cut-off value (for FSH). It is clear that most patients presented lower than expected values of $\mathrm{AMH}$ (30/35; 86\%) and AFC (20/21; 95\%). Figure 3 also highlights the fact that the levels of AMH and AFC were lower than expected in many of the patients who recovered regular menses.

\section{Recovery of ovarian function (ROF)}

At their last available follow-up, ten women (ages of 3039 years) had not recovered their ovarian function (10/ 
Table 1 Baseline demographic, obstetric, fertility preservation and treatment characteristics of the study participants $(n=38)$

\begin{tabular}{|c|c|}
\hline \multicolumn{2}{|l|}{ Characteristics } \\
\hline $\begin{array}{l}\text { Mean age } \\
\text { [median] (years) }\end{array}$ & $\begin{array}{l}32.9 \pm 3.5 \\
{[33.0]}\end{array}$ \\
\hline $\begin{array}{l}\text { Married/with } \\
\text { partner; n (\%) }\end{array}$ & $28(74)$ \\
\hline Childless; n (\%) & $25(66)$ \\
\hline $\begin{array}{l}\text { Overweight / } \\
\text { Obese; n (\%) }\end{array}$ & $9(24)$ \\
\hline $\begin{array}{l}\text { Former/current } \\
\text { smokers; } n(\%)\end{array}$ & $11(29)$ \\
\hline \multicolumn{2}{|l|}{$\begin{array}{l}\text { Fertility preservation; } \\
\mathrm{n}(\%)\end{array}$} \\
\hline No & $9(24)$ \\
\hline Yes & $29(76)$ \\
\hline Embryo $C P$ & 2 \\
\hline Oocyte CP & 25 \\
\hline Ovarian tissue $C P$ & 2 \\
\hline GnRH agonist & 2 \\
\hline \multicolumn{2}{|l|}{$\begin{array}{l}\text { Tumour biology; } \\
\text { n (\%) }\end{array}$} \\
\hline HR-positive & $15(39)$ \\
\hline HER -positive & $5(13)$ \\
\hline Triple negative & $9(24)$ \\
\hline Triple positive & $9(24)$ \\
\hline \multicolumn{2}{|l|}{$\begin{array}{l}\text { Type of systemic } \\
\text { treatments; } n \text { (\%) }\end{array}$} \\
\hline CT only & $8(21)$ \\
\hline $\mathrm{CT}+\mathrm{HT}$ & $16(42)$ \\
\hline$C T+\pi$ & $5(13)$ \\
\hline$C T+T+H T$ & $9(24)$ \\
\hline \multicolumn{2}{|l|}{ CT type; n (\%) } \\
\hline Neoadjuvant & $21(55)$ \\
\hline Adjuvant & $17(45)$ \\
\hline \multicolumn{2}{|l|}{ Type of CT regimen; $n$ (\%) } \\
\hline $\begin{array}{l}\text { Anthracycline-based } \\
\text { (FEC/AC/EC) + sequential } \\
\text { Paclitaxel/Docetaxel }\end{array}$ & $32(84)$ \\
\hline Taxane-based & $6(16)$ \\
\hline \multicolumn{2}{|l|}{$\begin{array}{l}\text { Type of HT; } \\
\mathrm{n}(\%)(n=25)\end{array}$} \\
\hline Tamoxifen only & $7(28)$ \\
\hline Tamoxifen + GnRHa & $10(40)$ \\
\hline Aromatase inhibitor only & $1(4)$ \\
\hline $\begin{array}{l}\text { Aromatase inhibitor } \\
+ \text { GnRHa }\end{array}$ & $5(20)$ \\
\hline GnRHa only & $2(8)$ \\
\hline
\end{tabular}

Data are presented as mean \pm SD or $n$ $B M I$ Body Mass Index, CT Chemotherapy, HC Hormonal contraception HER2 Human Epidermal growth factor Receptor-type 2, HR hormonal receptors

$H T$ hormonal therapy, GnRHa Gonadotropin-Releasing Hormone agonist $\Pi T$ targeted therapy
19; 53\%). Two of these women had not preserved fertility before CT. Five of them reported amenorrhea, three irregular menses and all presented AMH levels below the LoQ and/or FSH levels consistent with ovarian failure. In a total of 19 patients $(n=19)$, ROF was not evaluated as they were under HT and presented premenopausal levels of FSH.

In contrast, nine women met the criteria for ovarian function recovery at their last follow-up (9/19; 47\%). They were aged 25 to 38 years at recruitment and most presented normal/high levels of OR at baseline. Four of these women got pregnant at some point after CT. Two of them were under therapy with trastuzumab at the time of pregnancy and reported either spontaneous or medically-induced abortions. Pregnancy outcome was not known in the other two patients. Three of the woman who got pregnant had normal/high levels of OR markers at baseline. The only patient with low OR at baseline was treated with a taxane-only $\mathrm{CT}$ regimen.

\section{Premature ovarian insufficiency (POI)}

A total of five patients met the defined criteria for POI (5/22; 23\%), an outcome that was only assessed in patients who were not under ovarian suppression with GnRHa. Patients with POI had ages between 32 and 39 years at recruitment. Their levels of AMH remained below the LoQ and FSH was persistently high. One of them had not preserved her fertility before CT.

\section{Overall adverse reproductive health outcomes}

A summary of the various adverse reproductive health outcomes identified in this cohort of young BC women, at a mean of 18 months after $\mathrm{CT}$, is presented in Table 3.

\section{Patient-related factors and adverse reproductive health outcomes \\ Age at recruitment}

Age at recruitment was negatively correlated with the levels of AMH at the last follow-up $(n=35 ; \rho=-0.377$; $p=0.026)$. Moreover, AMH levels at the last follow-up were significantly higher in the group of younger patients $(n=16$; age $<33$ years) as compared to those aged 33 or more years $(n=19)$ and this difference was significant $(\mathrm{U}=70.5 ; p=0.002)$. In opposition, no significant correlation of patients' age with final AFC was found $(n=21 ; \rho=-0.183 ; p=0.427)$.

In this cohort of women with $\mathrm{BC}$, age at recruitment was significantly lower in patients who recovered ovarian function as compared to those who did not recover $(\mathrm{U}=20 ; p=0.038)$. However, in the subgroups of women with/without POI and women reporting/not regular menses, age at recruitment was not significantly different. 
Table 2 Mean and median levels of ovarian reserve markers (AMH, AFC and FSH) measured at baseline, during CT, 1 month and at a mean of 18 months after the end of CT

\begin{tabular}{cllll}
\hline & Baseline & During CT & 1 month after CT & Last available follow-up \\
\hline AMH ng/mL & $3.07 \pm 2.95(2.20)$ & $0.30 \pm 0.50(0.06)$ & $0.15 \pm 0.46^{1}(0.06)$ & $0.32 \pm 0.68^{1,3}(0.06)$ \\
Mean \pm SD (median) & $n=38$ & $n=21$ & $n=30$ & $n=34$ \\
AFC & $10.6 \pm 5.2(9.0)$ & $4.1 \pm 3.5(4.0)$ & $3.4 \pm 6.8^{2}(1.0)$ & $2.2 \pm 3.0^{1}(2.0)$ \\
Mean \pm SD (median) & $n=35$ & $n=19$ & $n=25$ & $n=21$ \\
FSH mlU/mL & $7.1 \pm 5.6(5.2)$ & $21.2 \pm 24.2(9.1)$ & $64.3 \pm 47.8^{1}(64)$ & $21.4 \pm 36.9^{4}(6.4)$ \\
Mean \pm SD (median) & $n=36$ & $n=21$ & $n=28$ & $n=35$ \\
\hline
\end{tabular}

AFC antral follicle count, $A M H$ anti-Mullerian hormone, $C T$ chemotherapy, FSH follicle-stimulating hormone

$S D$ standard deviation

${ }^{1}$ as compared to baseline, $\mathrm{p}<0.001 ;{ }^{2}$ as compared to baseline, $p=0.001 ;{ }^{3}$ as compared to the previous follow-up, $p=0.03$;

${ }^{4}$ as compared to the previous follow-up, $p<0.001$

\section{Baseline ovarian reserve}

A significant positive correlation between $\mathrm{AMH}$ levels at baseline and the last follow-up was found $(n=35 ; \rho=$ 0.517; $p=0.001)$. Levels of AMH at the last follow-up were also higher in the subgroup of patients with a baseline $\mathrm{AMH}$ above $2.2 \mathrm{ng} / \mathrm{mL}$ (the median for the cohort). In contrast, no significant correlation was found between baseline and final AFC $(n=20 ; \rho=0.275 ; p=0.241)$.
Baseline AMH levels also influenced the likelihood of recovering ovarian function, experiencing POI or reaching postmenopausal FSH levels: baseline AMH levels were significantly higher in the subgroup of women who recovered ovarian function $(n=19 ; \mathrm{U}=19.5 ; p=0.037)$ and significantly lower in patients with POI or menopausal FSH levels at the last follow-up $(n=22 ; \mathrm{U}=12, p=0.017$ and $n=19 ; \mathrm{U}=15, p=0.022$, respectively). Significant

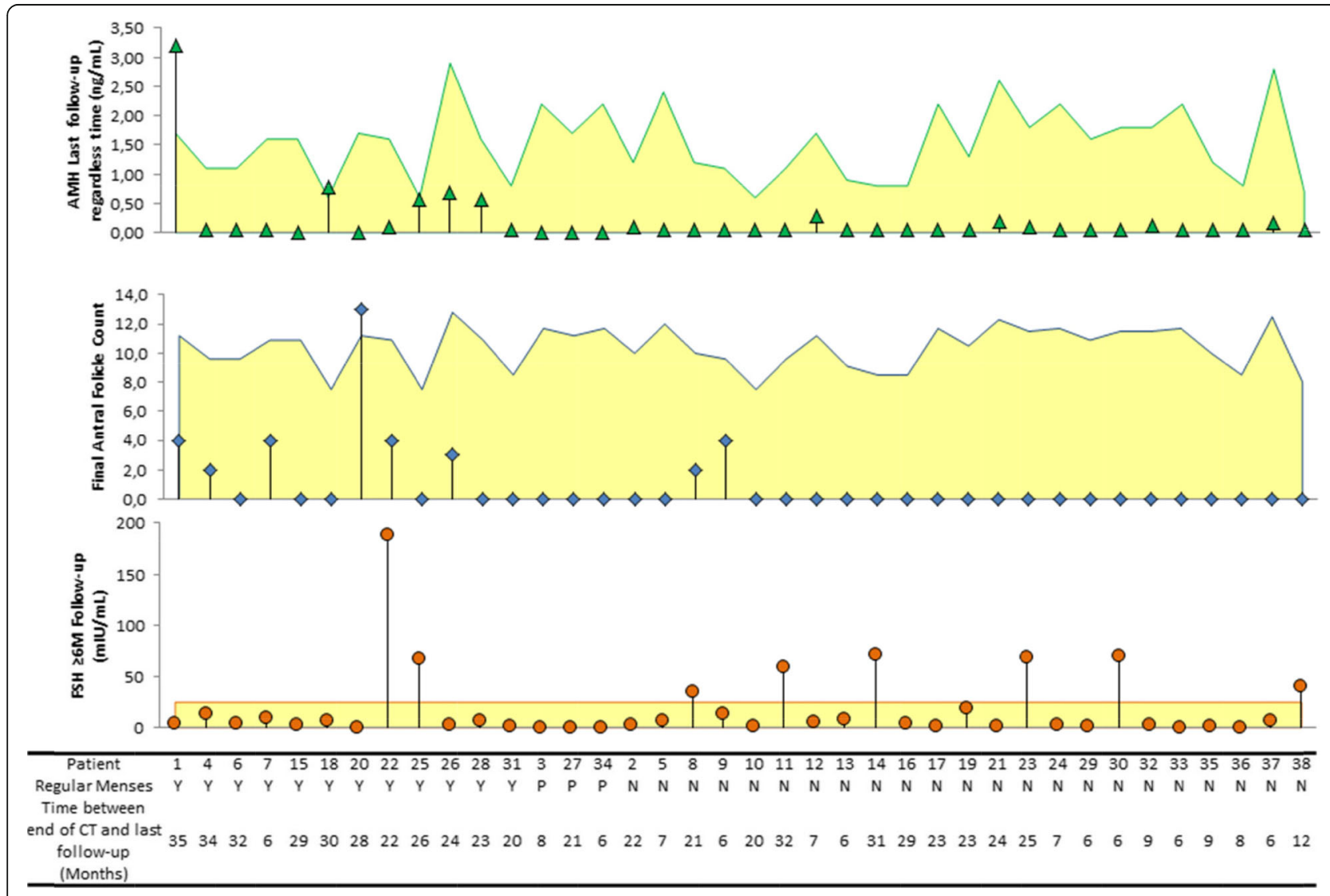

Legend: AFC - Antral Follicle Count; AMH - Anti-Mullerian Hormone; CT - chemotherapy; FSH - Follicle-stimulating Hormone; $\mathrm{N}$ - No; Y - Yes

Fig. 3 Patients' levels of OR markers at the last follow-up, ordered according to menstruation status (Y/N), and their comparison with the corresponding expected levels for age $(\mathrm{AMH}, \mathrm{AFC})$ or the cut-off value of $25 \mathrm{mlU} / \mathrm{mL}(\mathrm{FSH})$ 
Table 3 Percentage of patients in which the several adverse reproductive health outcomes were identified, at the last follow-up

\begin{tabular}{llllllll}
\hline Adverse outcome & $\begin{array}{l}\text { Oligo/ } \\
\text { amenorrhea }\end{array}$ & $\begin{array}{l}\mathrm{AMH}< \\
\mathrm{LOQ}\end{array}$ & $\begin{array}{l}\mathrm{AMH}< \\
\text { expected for } \\
\text { age }\end{array}$ & $\begin{array}{l}\text { AFC < expected } \\
\text { for age }\end{array}$ & $\begin{array}{l}\mathrm{FSH}>25 \\
\mathrm{mIU} / \mathrm{mL}\end{array}$ & $\begin{array}{l}\text { No recovery of } \\
\text { ovarian function }\end{array}$ & $\begin{array}{l}\text { Premature Ovarian } \\
\text { Insufficiency }\end{array}$ \\
\hline $\begin{array}{l}\text { Percentage of patients } \\
\text { presenting the outcome } \\
\text { (total number of patients } \\
\text { evaluated) }\end{array}$ & $71 \%(35)$ & $55 \%(38)$ & $86 \%(35)$ & $95 \%(21)$ & $25 \%(36)$ & $53 \%(19)$ & $23 \%(22)$ \\
\hline
\end{tabular}

AFC Antral Follicle Count, AMH Anti-Mullerian Hormone, FSH Follicle-Stimulating Hormone, LoQ Limit of Quantification

differences in AFC at baseline were only found between the groups of patients with/without POI at the last followup $(\mathrm{U}=9.5 ; p=0.032)$.

\section{Treatment-related factors and adverse reproductive health outcomes \\ Chemotherapy regimens}

No significant differences were found when comparing OR levels at the last follow-up in specific subgroups of CT (FEC-taxane, EC/AC-taxane, taxane without anthracycline, taxane-only and others). Nevertheless, in the subgroup of patients treated with sequential taxane $(n=$ $17)$, levels of $A M H$ were significantly lower after exposure to taxane $(\mathrm{z}=-2.2 ; p=0.028)$. The only $\mathrm{CT}$ regimen in which no negative outcome was identified was the paclitaxel-only regimen $(n=2)$. In this group, one patient got pregnant and the other recovered regular menses and normal expected OR levels.

No significant correlations were found between the number of weeks of exposure to $\mathrm{CT}$ and the levels of $\mathrm{AMH}$ or AFC at the last follow-up.

\section{Treatment combinations, exposure to trastuzumab and to hormonal therapy}

$\mathrm{AMH}$ levels at the last follow-up were compared in the groups treated with the four different combinations of systemic treatments. AMH was significantly higher in the group treated with $\mathrm{CT}+\mathrm{TT}(n=3)$ as compared to the groups exposed to CT only $(n=7)(\mathrm{U}=2 ; p=0.046)$ and to $\mathrm{CT}+\mathrm{HT}(n=16)(\mathrm{U}=0 ; p=0.002)$. In accordance with these results, we also found that $\mathrm{AMH}$ levels at the last follow-up were higher in all patients treated with trastuzumab $(n=12)$ as compared to those not exposed $(\mathrm{U}=84.5 ; p=0.036)$. No significant differences in mean age, baseline $\mathrm{AMH}$ levels or time to follow-up were found between these two groups.

Patients that were under treatment with any type of $\mathrm{HT}$ at the last follow-up exhibited significantly lower AMH $(\mathrm{U}=88 ; p=0.05)$ and FSH $(\mathrm{U}=83 ; p=0.056)$, although these groups were not different regarding their baseline age or AMH levels. When comparing the same OR markers in patients exposed/not exposed to GnRHa at the last follow-up, no significant differences in $\mathrm{AMH}$ levels were found, although FSH remained lower in those under ovarian suppression $(\mathrm{U}=57 ; p=0.002)$.

\section{Discussion}

\section{Adverse reproductive health outcomes}

It is of concern that more than half of the young premenopausal BC patients in this cohort did not recover ovarian function $(10 / 19 ; 53 \%)$, at a mean of 18 months after the end of CT. Additionally, we have identified POI in five women, which represent $23 \%(5 / 22)$ of those who could be evaluated for this outcome. A diagnosis of POI has a significant negative impact on the psychological wellbeing and quality of life as women may also experience genitourinary symptoms and present a reduced bone mineral density and an increased cardiovascular risk [25]. A considerable number of patients in our study were not evaluated for recovery or POI due to exposure to $\mathrm{HT}$, so it is likely that the incidence of these adverse outcomes would increase with a longer follow-up. Other studies have shown that ovarian function recovery may occur up to 2 years after the end of CT in women with BC [26-28], so we anticipate that most women in this cohort have now a very low, if any, chance of recovery. A similar prevalence of POI in young BC patients was observed for the control group of the OPTION trial (6/ $30 ; 20 \%)$ [29]. Our results are also in accordance with the subsequent data analysis of this trial by Anderson and colleagues [30], that concluded that women who developed POI had lower pre-treatment AMH concentrations than those who did not.

At the last follow-up, other adverse reproductive health outcomes are noteworthy: i) only one woman recovered her baseline AMH levels, ii) only five presented AMH levels considered normal according to age and iii) serum AMH was below the LoQ in $60 \%$ of the participants. Moreover, ten patients presented altered OR markers despite the recovery of regular menses, in line with other published studies [31, 32]. Nevertheless, four women became pregnant during the course of the study. Similarly to previous studies $[19,33]$, pregnancy occurred regardless of the low levels of OR.

\section{Patient-related factors}

In our very young cohort that may best represent the group of $\mathrm{BC}$ patients who engage in fertility counselling, age and baseline $\mathrm{AMH}$ were positively correlated with $\mathrm{AMH}$ levels at the last follow-up and the participants who recovered ovarian function were younger. Our 
results confirm $\mathrm{AMH}$ as the most sensitive marker of ovarian damage in $\mathrm{BC}$ patients exposed to $\mathrm{CT}$ and reinforce the potential usefulness of $\mathrm{AMH}$ as a predictor of ovarian function after $\mathrm{CT}$, in line with other studies where pre-CT level of AMH was associated with the occurrence of amenorrhea [34] or with post-CT AMH levels $[19,20]$.

\section{Treatment-related factors}

The addition of taxanes to anthracycline-based regimens has been associated with an increased negative impact of CT on fertility in several published clinical studies $[7,35,36]$ and meta-analysis [37], despite a few studies reporting opposite results [28, 38]. In our cohort, we found significant differences in the levels of AMH before and after the administration of the taxane.

One of the possible ways to overcome the negative effects of CT treatments in fertility is to select less gonadotoxic CT regimens. In our study, no adverse reproductive health outcome was observed in the two participants treated with the weekly paclitaxel regimen. These results are in accordance with those from the APT trial [39], where the weekly paclitaxel regimen seemed to have caused a less pronounced gonadotoxic effect. Further prospective controlled studies are needed to test this theory.

An interesting and somehow unexpected result of our investigation was the significant higher AMH levels in patients treated with trastuzumab. Trastuzumab is a monoclonal antibody that targets HER2-expressing tumour cells, and pre-clinical reproductive studies showed no evidence of impaired fertility [40]. Our results concur for the lack of gonadotoxicity that was already pointed by other clinical studies $[7,41]$ and add further data to the hypothesis of trastuzumab as a protector of ovarian vasculature from CT-induced damage [8]. In this study by Ben-Aharon and colleagues, a milder decrease in ovarian blood flow was seen in patients treated with trastuzumab as compared to those treated with CT only. The relevance of our observation is also supported by the results of a recently published crosssectional analysis, where exposure to trastuzumab was associated with increased AMH in BC survivors with normal menstrual cycles $(n=25)$ [42]. Moreover, this finding corroborates the previously mentioned outcomes of the APT trial [39]. There is a clear need for further investigations to ascertain this protective effect and to clarify the potential mechanism of action of trastuzumab.

In our study, we also found evidence of the influence of HT in the levels of OR markers: patients under therapy with tamoxifen, aromatase inhibitor and/or GnRHa at the last follow-up exhibited significantly lower levels of $\mathrm{AMH}$ and $\mathrm{FSH}$, despite no differences in their baseline ages and $\mathrm{AMH}$ levels were found. So, premenopausal FSH levels in BC patients under HT may be falsely reassuring [43]. When the isolated effect of ovarian suppression with GnRHa was investigated, only FSH levels remained different. Previous studies have also reported that patients under treatment with tamoxifen and/or a GnRHa may experience reduced FSH levels [22, 33, 44]. Regarding the influence of GnRHa on $\mathrm{AMH}$, some authors believe they have no direct effect on OR, due to the absence of FSH, LH, or GnRH receptors in primordial follicles [45] but others have reported reduced AMH levels in patients under ovarian suppression $[20,24]$. Further investigation is needed to confirm $\mathrm{AMH}$ as a reliable marker in this setting.

\section{Limitations}

This small cohort study may have lacked statistical power to detect differences between treatment combinations and different $\mathrm{CT}$ regimens. In view of this limitation, we have decided not to develop predictive models or conduct multivariate analysis.

Our results might also have been influenced by the low baseline OR levels seen in some participants, although the median AMH level of $2.2 \mathrm{ng} / \mathrm{mL}$ was similar to levels reported in other studies in younger $\mathrm{BC}$ patients [26].

Two participants in our study performed ovarian tissue cryopreservation (OTCP) which may have further contributed to reduce their OR. According to the recent study by Lantsberg et al. [46], that included 203 participants who performed OTCP, women with a breast cancer diagnosis and those under 30 years of age are more likely to conceive naturally and consequently less likely to need ovarian tissue transplantation. We were not able to confirm the influence of this FP technique on the levels of OR markers but it is important to notice that the two women who performed OTCP were over the age of 30 at diagnosis and presented lower than expected AMH level at baseline.

Other major limitation is the fact that a very significant number of participants $(n=20)$ was still under the influence of HT at the last follow-up, which restricted the assessment of some of the outcomes. Nevertheless, this limitation also occurs in clinical practice: many $\mathrm{BC}$ patients remain in treatment with HT for several years and the identification of reliable markers to assess their menopausal status is still an unsolved issue [47, 48].

\section{Conclusions}

Our study in young women with BC revealed significant effects of systemic treatments on several reproductive outcomes and confirmed their strong relation with patient's age and baseline level of AMH. We have confirmed AMH as the most sensitive marker of $\mathrm{OR}$ in young premenopausal women with $\mathrm{BC}$ and its 
effectiveness as a predictor of ovarian function recovery and occurrence of POI.

The results of this study point to the possibility of a lower gonadotoxicity when patients are treated with less complex CT regimens or when treatment includes targeted therapy with trastuzumab. Also, this investigation highlights the lack of reliable OR markers in women with $\mathrm{BC}$ under treatment with $\mathrm{HT}$ and the consequent risk of undetected ovarian failure in this population.

Overall, our results strongly emphasize the relevance of pre-treatment counselling regarding infertility risks and fertility preservation for all premenopausal $\mathrm{BC}$ patients, with a special emphasis on older patients or those with low baseline OR.

\section{Abbreviations}

AFC: Antral follicle count; AMH: Anti-Mullerian hormone; BC: Breast cancer; CFP: Center of Fertility Preservation; CT: Chemotherapy; FP: Fertility preservation; FSH: Follicle-stimulating hormone; GnRHa : Gonadotropinreleasing hormone agonist; HT: Hormonal therapy; LoQ: Limit of quantification; OR: Ovarian reserve; POI: Premature ovarian insufficiency

\section{Acknowledgements}

The authors would like to thank to Professor Paula Fresco for the careful review of the manuscript.

\section{Authors' contributions \\ CS was involved in conception and design of the study, data collection, data analysis and interpretation and in drafting/revising and giving final approval of the manuscript. ACRR was involved in conception and design of the study, in the interpretation of the data and in revising and giving final approval of the manuscript. SRS was involved in data collection and in drafting/revising and giving final approval of the manuscript. MMR was involved in data analysis and interpretation and in drafting/revising and giving final approval of this manuscript. TAS was involved in conception and design of the study, data collection, data analysis and interpretation and in drafting/revising and giving final approval of this manuscript.}

\section{Funding}

This work received no funding.

\section{Availability of data and materials}

The datasets collected and/or analyzed during the current study are available from the corresponding author on reasonable request.

\section{Ethics approval and consent to participate}

The study has received approval by the Ethical Committee of CHUC, EPE. All participants signed an informed consent.

\section{Competing interests}

The authors declare that they have no competing interests.

\footnotetext{
Author details

'Pharmacology Department, Faculty of Pharmacy, University of Coimbra, Coimbra, Portugal. ${ }^{2}$ Pharmaceutical Services, Centro Hospitalar e Universitário de Coimbra (CHUC), EPE, Coimbra, Portugal. ${ }^{3}$ Institute for Clinical and Biomedical Research, Faculty of Medicine, University of Coimbra, Coimbra, Portugal. ${ }^{4}$ IVI Clinic, Lisbon, Portugal. ${ }^{5}$ Reproductive Medicine Unit, Centro Hospitalar e Universitário de Coimbra (CHUC), EPE, Coimbra, Portugal. ${ }^{6}$ Center for Research in Neuropsychology and Cognitive and Behavioural Intervention, Coimbra, Portugal. "7Faculty of Medicine, University of Coimbra, Coimbra, Portugal. ${ }^{8}$ Center for Neuroscience and Cell Biology, University of Coimbra, Coimbra, Portugal.
}

Received: 30 July 2019 Accepted: 10 October 2019

Published online: 31 October 2019

\section{References}

1. International Agency for Research on Cancer. Breast Cancer Fact Sheet: Estimated Incidence, Mortality and Prevalence Worldwide in 20122012 [January 2018]. Available from: http://globocan.iarc.fr/Pages/fact_sheets_ cancer.aspx. Accessed Jan 2018.

2. Ribnikar D, Ribeiro JM, Pinto D, Sousa B, Pinto AC, Gomes E, et al. Breast cancer under age 40: a different approach. Curr Treat Options in Oncol. 2015:16(4):16.

3. Assi HA, Khoury KE, Dbouk H, Khalil LE, Mouhieddine TH, El Saghir NS. Epidemiology and prognosis of breast cancer in young women. J Thorac Dis. 2013;5(Suppl 1):S2-8.

4. Anders CK, Johnson R, Litton J, Phillips M, Bleyer A. Breast cancer before age 40 years. Sem Oncol. 2009;36(3):237-49.

5. UK Cancer Research. Breast cancer survival statistics by age: Cancer Research UK; 2013 [updated 11 May 2016January 2018] Available from:http://www. cancerresearchuk.org/health-professional/cancer-statistics/statistics-bycancer-type/breast-cancer/survival\#heading-One. Accessed Jan 2018.

6. Freour T, Barriere P, Masson D. Anti-mullerian hormone levels and evolution in women of reproductive age with breast cancer treated with chemotherapy. Eur J Cancer. 2017;74:1-8.

7. Abusief ME, Missmer SA, Ginsburg ES, Weeks JC, Partridge AH. The effects of paclitaxel, dose density, and trastuzumab on treatment-related amenorrhea in premenopausal women with breast cancer. Cancer. 2010;116(4):791-8.

8. Ben-Aharon I, Granot T, Meizner I, Hasky N, Tobar A, Rizel S, et al. Long-term follow-up of chemotherapy-induced ovarian failure in young breast Cancer patients: the role of vascular toxicity. Oncol. 2015;20(9):985-91.

9. Ruddy KI, Partridge AH. Fertility (male and female) and menopause. J Clin Oncol. 2012;30(30):3705-11.

10. Nelson SM. Biomarkers of ovarian response: current and future applications. Fertil Steril. 2013:99(4):963-9.

11. Partridge AH, Ruddy KJ, Gelber S, Schapira L, Abusief M, Meyer M, et al. Ovarian reserve in women who remain premenopausal after chemotherapy for early stage breast cancer. Fertil Steril. 2010;94(2):638-44.

12. Su HI, Chung K, Sammel MD, Gracia CR, DeMichele A. Antral follicle count provides additive information to hormone measures for determining ovarian function in breast cancer survivors. Fertil Steril. 2011;95(5):1857-9.

13. Broekmans FJ, de Ziegler D, Howles CM, Gougeon A, Trew G, Olivennes F. The antral follicle count: practical recommendations for better standardization. Fertil Steril. 2010;94(3):1044-51.

14. Seifer DB, Baker VL, Leader B. Age-specific serum anti-Mullerian hormone values for 17,120 women presenting to fertility centers within the United States. Fertil Steril. 2011;95(2):747-50.

15. Almog B, Shehata F, Shalom-Paz E, Tan SL, Tulandi T. Age-related normogram for antral follicle count: McGill reference guide. Fertil Steril. 2011:95(2):663-6.

16. Su HI. Measuring ovarian function in young cancer survivors. Min Endocrin. 2010;35(4):259-70.

17. Rossi E, Morabito A, Di Rella F, Esposito G, Gravina A, Labonia V, et al. Endocrine effects of adjuvant letrozole compared with tamoxifen in hormone-responsive postmenopausal patients with early breast cancer: the HOBOE trial. J Clin Oncol. 2009;27(19):3192-7.

18. Kumar P, Sharma A. Gonadotropin-releasing hormone analogs: understanding advantages and limitations. J Hum Reprod Sci. 2014:7(3):170-4.

19. Dezellus A, Barriere P, Campone M, Lemanski C, Vanlemmens L, Mignot L, et al. Prospective evaluation of serum anti-Mullerian hormone dynamics in 250 women of reproductive age treated with chemotherapy for breast cancer. Eur J Cancer. 2017:79:72-80.

20. Trapp E, Steidl J, Rack B, Kupka MS, Andergassen U, Juckstock J, et al. AntiMullerian hormone (AMH) levels in premenopausal breast cancer patients treated with taxane-based adjuvant chemotherapy - a translational research project of the SUCCESS a study. Breast. 2017;35:130-5.

21. Shandley LM, Spencer JB, Fothergill A, Mertens AC, Manatunga A, Paplomata $E$, et al. Impact of tamoxifen therapy on fertility in breast cancer survivors. Fertil Steril. 2017;107(1):243-52 e5.

22. Su HI, Maas K, Sluss PM, Chang RJ, Hall JE, Joffe H. The impact of depot GnRH agonist on AMH levels in healthy reproductive-aged women. J Clin Endocrin Metab. 2013;98(12):E1961-6. 
23. Hagen CP, Sorensen $K$, Anderson RA, Juul A. Serum levels of antimullerian hormone in early maturing girls before, during, and after suppression with GnRH agonist. Fertil Steril. 2012;98(5):1326-30.

24. Anderson RA, Themmen AP, Al-Qahtani A, Groome NP, Cameron DA. The effects of chemotherapy and long-term gonadotrophin suppression on the ovarian reserve in premenopausal women with breast cancer. Hum Reprod. 2006;21(10):2583-92

25. Webber L, Davies M, Anderson R, Bartlett J, Braat D, Cartwright B, et al. ESHRE guideline: management of women with premature ovarian insufficiency. Hum Reprod. 2016;31(5):926-37.

26. Hamy AS, Porcher R, Cuvier C, Giacchetti S, Schlageter MH, Coussieu C, et al. Ovarian reserve in breast cancer: assessment with anti-Mullerian hormone. Reprod BioMed Online. 2014;29(5):573-80.

27. Jacobson MH, Mertens AC, Spencer JB, Manatunga AK, Howards PP. Menses resumption after cancer treatment-induced amenorrhea occurs early or not at all. Fertil Steril. 2016;105(3):765-72 e4

28. Sukumvanich $P$, Case LD, Van Zee $K$, Singletary SE, Paskett ED, Petrek $J A$, et al. Incidence and time course of bleeding after long-term amenorrhea after breast cancer treatment: a prospective study. Cancer. 2010;116(13):3102-11.

29. Leonard RCF, Adamson DJA, Bertelli G, Mansi J, Yellowlees A, Dunlop J, et al. $\mathrm{GnRH}$ agonist for protection against ovarian toxicity during chemotherapy for early breast cancer: the Anglo Celtic group OPTION trial. Ann Oncol. 2017;28(8):1811-6.

30. Anderson RA, Mansi J, Coleman RE, Adamson DJA, Leonard RCF. The utility of anti-Mullerian hormone in the diagnosis and prediction of loss of ovarian function following chemotherapy for early breast cancer. Eur J Cancer. 2017;87:58-64.

31. Letourneau JM, Ebbel EE, Katz PP, Oktay KH, McCulloch CE, Ai WZ, et al. Acute ovarian failure underestimates age-specific reproductive impairment for young women undergoing chemotherapy for cancer. Cancer. 2012; 118(7):1933-9.

32. Peigne $M$, Decanter $C$. Serum AMH level as a marker of acute and longterm effects of chemotherapy on the ovarian follicular content: a systematic review. Reprod Biol Endocrin. 2014;12:26.

33. Hamy AS, Porcher R, Eskenazi S, Cuvier C, Giacchetti S, Coussy F, et al. AntiMullerian hormone in breast cancer patients treated with chemotherapy: a retrospective evaluation of subsequent pregnancies. Reprod BioMed Online. 2016;32(3):299-307.

34. Anderson RA, Wallace WH. Antimullerian hormone, the assessment of the ovarian reserve, and the reproductive outcome of the young patient with cancer. Fertil Steril. 2013;99(6):1469-75.

35. Berliere $M$, Dalenc F, Malingret N, Vindevogel A, Piette $P$, Roche $H$, et al. Incidence of reversible amenorrhea in women with breast cancer undergoing adjuvant anthracycline-based chemotherapy with or without docetaxel. BMC Cancer. 2008:8:56.

36. Perdrix A, Saint-Ghislain M, Degremont M, David M, Khaznadar Z, Loeb A, et al. Influence of adjuvant chemotherapy on anti-Mullerian hormone in women below 35 years treated for early breast cancer. Reprod BioMed Online. 2017;35(4):468-74.

37. Zhao J, Liu J, Chen K, Li S, Wang Y, Yang Y, et al. What lies behind chemotherapy-induced amenorrhea for breast cancer patients: a metaanalysis. Breast Cancer Res Treat. 2014;145(1):113-28.

38. Perez-Fidalgo JA, Rosello S, Garcia-Garre E, Jorda E, Martin-Martorell $P$, Bermejo B, et al. Incidence of chemotherapy-induced amenorrhea in hormone-sensitive breast cancer patients: the impact of addition of taxanes to anthracycline-based regimens. Breast Cancer Res Treat. 2010; 120(1):245-51.

39. Ruddy KJ, Guo H, Barry W, Dang CT, Yardley DA, Moy B, et al. Chemotherapy-related amenorrhea after adjuvant paclitaxel-trastuzumab (APT trial). Breast Cancer Res Treat. 2015;151(3):589-96.

40. Lorenzi $\mathrm{E}$, Simonelli M, Santoro A. Infertility risk and teratogenicity of molecularly targeted anticancer therapy: a challenging issue. Crit Rev Oncol/ Hematol. 2016;107:1-13.

41. Meng K, Tian W, Zhou M, Chen H, Deng Y. Impact of chemotherapyinduced amenorrhea in breast cancer patients: the evaluation of ovarian function by menstrual history and hormonal levels. World J Surg Oncol. 2013;11:101

42. Morarji K, McArdle O, Hui K, Gingras-Hill G, Ahmed S, Greenblatt EM, et al. Ovarian function after chemotherapy in young breast cancer survivors. Curr Oncol. 2017;24(6):e494-502.
43. Vriens IJ, De Bie AJ, Aarts MJ, de Boer M, van Hellemond IE, Roijen JH, et al. The correlation of age with chemotherapy-induced ovarian function failure in breast cancer patients. Oncotarget. 2017;8(7):11372-9.

44. Su HC, Haunschild C, Chung K, Komrokian S, Boles S, Sammel MD, et al. Prechemotherapy antimullerian hormone, age, and body size predict timing of return of ovarian function in young breast cancer patients. Cancer. 2014; 120(23):3691-8.

45. Oktay K, Bedoschi G. Appraising the biological evidence for and against the utility of GnRHa for preservation of fertility in patients with Cancer. J Clin Oncol. 2016;34(22):2563-5.

46. Lantsberg D, Farhi A, Zaslavsky-Paltiel I, Silverman BG, Lerner-Geva L, Orvieto R. Deliveries following fertility preservation by ovarian tissue cryopreservation without autotransplantation-what should be expected? J Assist Reprod Genet. 2019;36(2):335-40.

47. Amir E, Freedman O, Allen L, Colgan T, Clemons M. Defining ovarian failure in amenorrheic young breast cancer patients. Breast. 2010;19(6):545-8.

48. Krekow LK, Hellerstedt BA, Collea RP, Papish S, Diggikar SM, Resta R, et al. Incidence and predictive factors for recovery of ovarian function in Amenorrheic women in their 40s treated with Letrozole. J Clin Oncol. 2016; 34(14):1594-600.

\section{Publisher's Note}

Springer Nature remains neutral with regard to jurisdictional claims in published maps and institutional affiliations.
Ready to submit your research? Choose BMC and benefit from:

- fast, convenient online submission

- thorough peer review by experienced researchers in your field

- rapid publication on acceptance

- support for research data, including large and complex data types

- gold Open Access which fosters wider collaboration and increased citations

- maximum visibility for your research: over $100 \mathrm{M}$ website views per year

At $\mathrm{BMC}$, research is always in progress.

Learn more biomedcentral.com/submissions 